\title{
Effect of Static Rotor Eccentricity on End Winding Forces and Vibration Wearing
}

\author{
Hong-Chun Jiang $\mathbb{D}^{1},{ }^{1}$ Gui-Ji Tang $\mathbb{D}^{1}{ }^{1}$ Yu-Ling He $\mathbb{D}^{1},{ }^{1}$ Kai Sun $\mathbb{D}^{1},{ }^{1}$ Wei-Jun Li, ${ }^{2}$ \\ and Lun Cheng ${ }^{3}$ \\ ${ }^{1}$ Department of Mechanical Engineering, and the Hebei Key Laboratory of Electric Machinery and Failure Prevention, North China \\ Electric Power University, Baoding 071003, China \\ ${ }^{2}$ State Grid Zhejiang Electric Power Research Institute, Hangzhou 310014, China \\ ${ }^{3}$ State Grid Hebei Electric Power Supply Co., Ltd., Shijiazhuang 050022, China
}

Correspondence should be addressed to Yu-Ling He; heyuling1@163.com

Received 22 February 2021; Accepted 12 March 2021; Published 30 March 2021

Academic Editor: Hyeong Joon Ahn

Copyright (c) 2021 Hong-Chun Jiang et al. This is an open access article distributed under the Creative Commons Attribution License, which permits unrestricted use, distribution, and reproduction in any medium, provided the original work is properly cited.

\begin{abstract}
In order to study the vibration wearing regularity and the strength failure point of stator end windings before and after static rotor eccentricity, the three-dimensional electromagnetic forces and the subsequent mechanical responses are studied in this paper. The electromagnetic force, stress, and deformation on the end winding of the QFSN-600-2YHG turbo-generator are calculated by the finite element method (FEM) through an electromagnetic-structure coupling. The radial vibration characteristics of the winding are verified by experiments. It shows that the vibration wearing in the same layer is more serious than that between two neighboring layers. For different layers, the interphase coils endure a larger wearing risk than the innerphase coils. Inside the same phase, the last coil along the rotating direction has the highest risk of insulation wearing. The occurrence of static rotor eccentricity will significantly increase the electromagnetic forces and the vibration amplitudes on some coils. The end-phase coil which is close to the minimum air-gap point is the most dangerous one due to the lasting overstresses and the intensified deformations.
\end{abstract}

\section{Introduction}

The stator windings are the key components which implement the energy conversion. As the capacity increases, the stator windings in generators, especially in large turbogenerators, will afford larger electromagnetic forces. Such electromagnetic forces will cause the winding to vibrate [1] and endure stresses [2, 3].

Scholars have paid much attention to the electromagnetic forces/stresses on end windings. Chow et al. used the integral-equation method to determine the magnetic field and the electromagnetic forces on conductors [4]. Khan et al. set up the force analysis model based on the image current analysis [5]. The key point of these two methods is to use Biot-Savart's law to calculate the magnetic field on the end region based on the integral performance. Albanese et al. further confirmed the effectiveness of such a method
[6]. The advantage of such a method is that it is able to obtain the magnetic flux density at an arbitrary point. Afterwards, the finite element method (FEM) was fast developed and more and more researchers employed FEM to study the electromagnetic forces. For instance, Kim et al. analyzed the distribution of the electromagnetic force on the end windings based on the Biot-Savart law and 3D FEM [7], while Fang et al. carry out the calculation of the stress distribution on end windings in a large water filling submersible motor during both steady state and transient operations $[8,9]$. Also, Salon et al. presented the winding force variation under the transient operation in larger turbine generators [10]. Besides the running conditions (steady state and transient case), it is also found that some other factors such as the speed, the power factor, the saturation of the stator teeth, the magnetic field distribution, the winding connection, and the shape of the salient poles will also affect the force magnitude 
$[11,12]$. Subsequently, to reduce the fluctuation of the resulting electromagnetic forces, Liang et al. designed a new structure of the stator windings according to the electromagnetic force characteristics [13]. Complementally, by analyzing the electromagnetic force of different rods at varied moments, Bao et al. found that the electromagnetic force mutation often occurs in the transition part of the involute [14]. Ohtaguro et al. studied the mechanical strain of the end windings in high-voltage rotating machines and employed the strain gauges for the validation test [15], finding that the strains of the stator end windings due to the electromagnetic forces will be larger as the machine starts. The authors have also carried out the 3D FEM calculation on the end winding forces as well as the mechanical response in 600 MW turbogenerators, getting that the nose part, the root, and the middle part are the most dangerous positions to be damaged [1].

In addition to the electromagnetic forces, stresses, and strains, there is still another key parameter, i.e., the winding vibrations. The electromagnetic forces and the vibrations in axial flux permanent magnet synchronous machines (PMSM) with three different winding types were calculated by $\mathrm{Lu}$ et al. based on the multiphysics analysis [16]. Patel and Butler employed the optical displacement follower to test the end winding vibrations in a large 2-pole generator [17]. It is found that the nominal vibration amplitude is about 76-102 $\mu \mathrm{m}$, while under the leading-power factor pattern, the vibration will be increased to $185 \mu \mathrm{m}$. Actually, more and more large generators have installed the opticalelectrical conversion type sensors such as the fiber optic accelerometers, to monitor the radial vibration of the end windings. Since the electromagnetic force on the end windings has the prominent 2nd harmonic, it is requested for large generators that the natural frequency of the end windings should be away from the 2nd harmonic frequency as much as possible [1]. To find out a more comprehensive result, Mori and Ishikawa clarified the relationship among the radial electromagnetic force, the natural frequencies, and the vibration velocities [18], while Yang and Chen presented the general expression of the frequency and the corresponding mode number of the radial force harmonics for a permanent magnet synchronous machine (PMSM) which had three-phase symmetrical double-layer windings [19]. In addition, Ishibashi et al. calculated the natural frequencies of the steel core and the windings, finding that as the configuration of the ring becomes more complex, the number of the natural frequencies will be increased, while the exact values of the natural frequencies will be decreased [20].

By far, most of the investigations on the end windings are focused on the normal conditions/nominal operations, while the faulty cases are paid with much less attention. It is found that the electromagnetic force on the end windings will be significantly increased in the 3-phase short circuit condition [21]. In the meantime, Li et al. have also discovered that the magnetic field in the end region will be greatly changed when synchronizing out of phase occurs, and the large impulse current may damage the winding insulation [22]. Moreover, it is also pointed out that either the short circuit degree or the short circuit position will affect the electromagnetic forces as well as the vibration characteristics of the end windings in synchronous generators [23]. The authors have also carried out some preresearches and found that the odd harmonics of the electromagnetic force will be increased, while the even harmonics will be decreased as the rotor winding interturn short circuit occurs [24]. Besides, the studies on the rotor vibration [25], the magnetic flux density [26], the phase current [27], the electromagnetic torque [28], the rotor vibration properties [29], and the shaft voltage [27, 30] under static air-gap eccentricity have also been presented. However, how will the end winding force change and how the vibration response varies in the static rotor eccentricity cases have still not been studied.

As the rotor eccentricity happens, the electromagnetic forces as well as the vibrations of some windings will be aggravated, and the subsequent insulation wearing failure may happen after a long-term performance. Since the rotor eccentricity is pretty common and exists in almost every generator, it is significant to study the winding force properties as well as the vibration responses. In this paper, we study the electromagnetic force properties and also the subsequent mechanical responses of the end windings in a $600 \mathrm{MW}$ turbo-generator. The remainder of this paper is constructed as follows. The qualitative formulas of the electromagnetic force on the end windings under static rotor eccentricity are derived in Section 2 , while the finite element analysis and the experimental study are carried out in Section 3 and Section 4, respectively. Based on the theoretical, the FEM, and the experimental study, the primary conclusions are finally drawn up in Section 5.

\section{Analysis on Electromagnetic Force}

The rotor winding distribution and the connection relationship are shown in Figures 1(a) and 1(b). The winding magnetomotive force (MMF) can be obtained based on the superposition principle. The MMF generated by the $i$ th coil is shown in Figure 1(c), and the MMF at an arbitrary point whose circumferential position angle is $\alpha$ (as shown in Figure $1(d)$ ) can be written as

$$
f_{r i}(\alpha)= \begin{cases}I_{r} w_{r}\left(1-\alpha_{i}\right), & {\left[-\alpha_{i} \pi, \alpha_{i} \pi\right]} \\ -I_{r} w_{r} \alpha_{i}, & \text { others }\end{cases}
$$

with

$$
\alpha_{i}= \begin{cases}\frac{\beta_{i}}{2}, & i=1 \text { to } 8 \\ 1-\frac{\beta_{i}}{2}, & i=9 \text { to } 16\end{cases}
$$

where $I_{r}$ and $w_{r}$ are the current and the number of turns, respectively, and $\beta_{i}$ is the ratio of the $i$ th rotor coil pitch to the pole pitch. The rotor winding MMF and its Fourier series can be written as

$$
f_{r}(\alpha)=\sum_{i=1}^{16} f_{r i}=\sum_{i=1}^{16}\left[\frac{A_{0}}{2}+\sum_{n=1}^{\infty}\left(A_{n} \cos n \alpha+B_{n} \sin n \alpha\right)\right],
$$




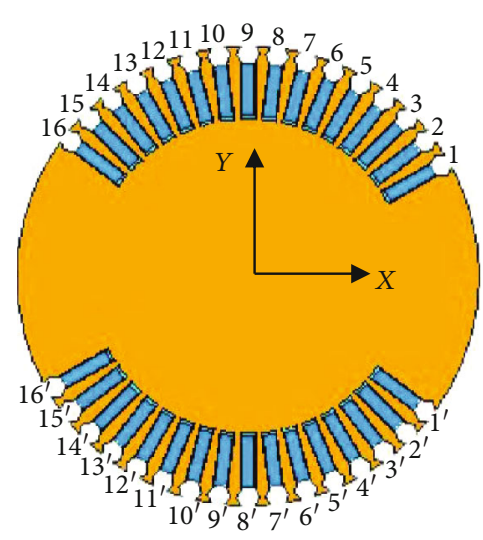

(a)

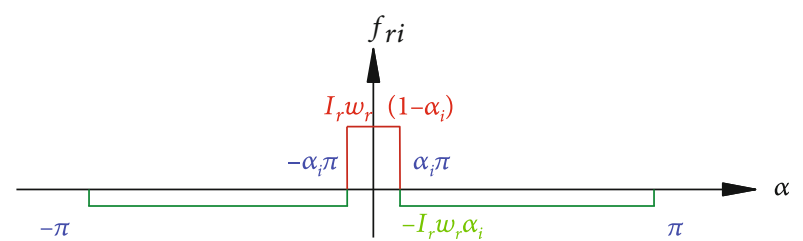

(c)

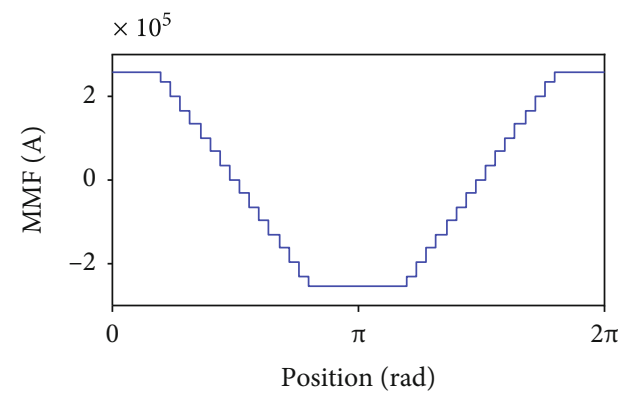

(e)

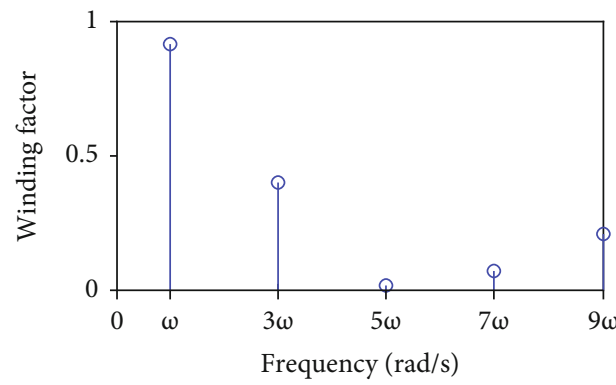

(g)

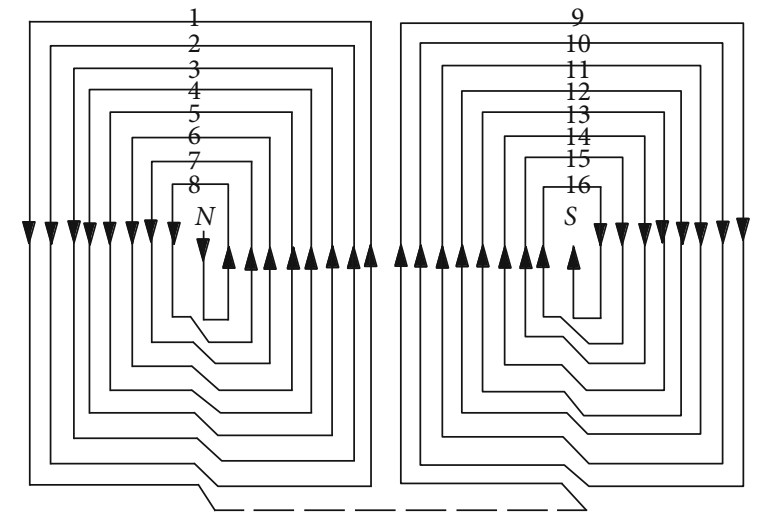

(b)

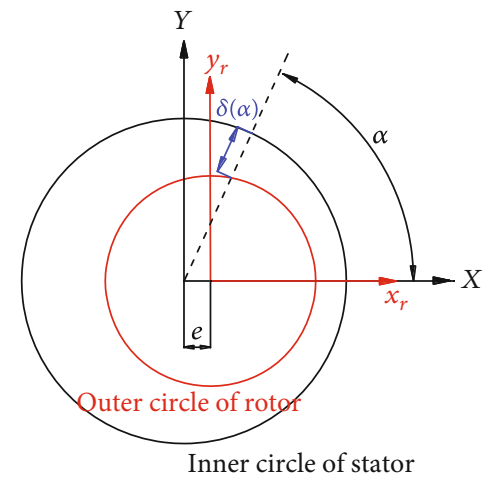

(d)

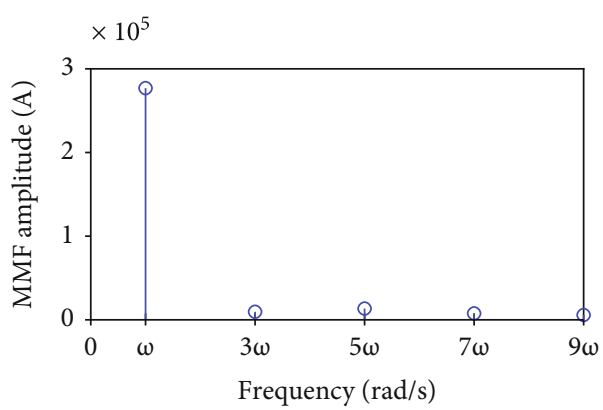

(f)

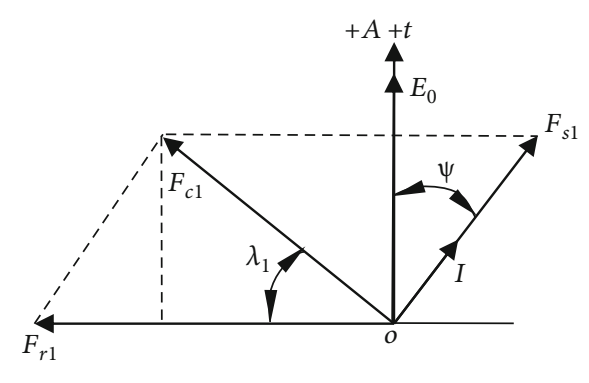

(h)

FIGURE 1: Air-gap and MMF: (a) sectional view of rotor winding distribution, (b) connection relationship of rotor windings, (c) MMF of the $i$ th rotor coil, (d) eccentric air-gap, (e, f) rotor winding MMF waveform and spectrum, (g) winding factor harmonics, and (h) relationship of rotor winding MMF and stator wingding MMF. 
where

$$
\left\{\begin{array}{l}
A_{0}=\frac{1}{2 \pi} \int_{-\pi}^{\pi} f_{r} d \alpha=0 \\
A_{n}=\frac{1}{\pi} \int_{-\pi}^{\pi} f_{r} \cos n \alpha d \alpha=\frac{2 I_{r} w_{r}}{n} \sin \left(n \alpha_{i} \pi\right) \\
B_{n}=\frac{1}{\pi} \int_{-\pi}^{\pi} f_{r} \sin n \alpha d \alpha=0
\end{array}\right.
$$

The factors $w_{r}$ and $\beta_{i}$ have the same values for the $i$ th and (17- $i$ )th coils, and the rotor is rotating at the angular frequency of $\omega(\omega=2 \pi f, f=50 \mathrm{~Hz})$. The rotor winding $\mathrm{MMF}$ can be reduced as

$$
\left\{\begin{array}{l}
f_{r}(\alpha, t)=\sum_{i=1}^{16} \sum_{n=1}^{\infty} \frac{2 I_{r} w_{r}}{n \pi} \sin \left(n \alpha_{i} \pi\right) \cos n(\omega t-\alpha)=\sum_{n=1,3,5 \ldots} F_{r n} \cos n(\omega t-\alpha), \\
F_{r n}=\sum_{i=1}^{8} \frac{4 I_{r} w_{r}}{n \pi} \sin \left(\frac{\beta_{i}}{2} n \pi\right) .
\end{array}\right.
$$

The MMF waveform and the spectrum are exhibited in Figures 1(e) and 1(f), respectively. It is shown that the MMF is a stair wave which mainly contains odd harmonic components.

The permeance per unit area (hereafter, it is written as unit permeance for short) in the air-gap is in inversed proportion to the radial air-gap length, which can be expanded via power series and written as

$$
\Lambda(\alpha)=\frac{\mu_{0}}{\delta(\alpha)}=\frac{\mu_{0}}{\delta_{0}(1-\varsigma \cos \alpha)} \approx \Lambda_{0}(1+\varsigma \cos \alpha),
$$

where $\Lambda_{0}=\mu_{0} / \delta_{0}$ is the normal unit permeance, $\zeta=e / \delta_{0}$ is the eccentricity rate, and $e$ is the eccentricity value, as indicated in Figure 1(d).

The magnetic flux density (MFD) of the air-gap can be obtained through multiplying MMF by the unit permeance, that is,

$$
\begin{aligned}
B_{r}(\alpha, t) & =f_{r}(\alpha, t) \Lambda(\alpha) \\
& =\Lambda_{0}(1+\varsigma \cos \alpha) \sum_{n=1,3,5 \cdots} F_{r n} \cos n(\omega t-\alpha) .
\end{aligned}
$$

Thus, the stator winding current can be written as

$$
\left\{\begin{array}{l}
I_{s}(t)=\frac{E(t)}{Z}=\sum_{n=1,3,5 \ldots} \frac{q w_{s} k_{w n} B_{r} L v}{Z}=\sum_{n=1,3,5 \ldots} I_{s n} \cos n\left(\omega t-\alpha-\psi-\frac{\pi}{2}\right), \\
I_{s n}=\frac{1}{|Z|} q w_{s} k_{w n} F_{r n} \Lambda_{0}(1+\varsigma \cos \alpha) L v,
\end{array}\right.
$$

where $E$ is the induced electromotive force, $L$ is the effective axial length of the winding, $v$ is the velocity that the coil bar cuts the magnetic flux lines, $Z$ is the reactance of the winding, $q$ is the slot number per phase, $w_{s}$ is the turn number per coil, $\psi$ is the internal power angle of the generator, and $k_{w n}$ is the winding factor of the $n$th harmonic. The winding factor can be described as

$$
k_{w n}=\frac{\sin n\left(90^{\circ} \cdot y / \tau\right) \sin \left(n q \alpha_{1} / 2\right)}{q \sin \left(n \alpha_{1} / 2\right)}, \quad n=1,3,5, \cdots
$$

where $\alpha_{1}$ is the angle between the two neighboring slots, $y$ is the stator coil pitch, and $\tau$ is the stator pole pitch. The harmonics of the winding factor are shown in Figure $1(\mathrm{~g})$.

The stator winding MMF can also be obtained according to the superposition principle. And it can be written as

$$
\left\{\begin{array}{l}
f_{s}(\alpha, t)=\sum_{n=1,3,5 \cdots} F_{s n} \cos n(\omega t-\alpha-\psi-0.5 \pi) \\
F_{s n}=\frac{1.35}{\sqrt{2}} I_{s n} w_{s} k_{w n} q
\end{array}\right.
$$

According to Equations (8) and (10) and Figures 1(f) and $1(\mathrm{~g})$, the stator winding current contains only odd harmonics, with the 1st harmonic as the primary one. Therefore, the MMF produced by the stator windings should also contain odd harmonics only, and the 1st harmonic should be the prominent. The static rotor eccentricity will generally affect the permeance but has little influence on the magnetomotive force (MMF) [14]. For the sake of analysis convenience, we ignore the higher-order harmonics, and the MMF at an arbitrary point which has the circumferential position angle of $\alpha$ can be written as

$$
\left\{\begin{array}{l}
f(\alpha, t)=\sum_{n=1,3,5 \ldots} F_{r n} \cos n(\omega t-\alpha)+F_{s n} \cos n(\omega t-\alpha-\psi-0.5 \pi)=\sum_{n=1,3,5 \ldots} F_{c n} \cos n\left(\omega t-\alpha-\lambda_{n}\right) \approx F_{c 1} \cos \left(\omega t-\alpha-\lambda_{1}\right) \\
F_{c 1}=\sqrt{F_{s 1}^{2} \cos ^{2} \psi+\left(F_{r 1}-F_{s 1} \sin \psi\right)^{2}} \\
\lambda_{1}=\arctan \frac{F_{s 1} \cos \psi}{F_{r 1}-F_{s 1} \sin \psi}
\end{array}\right.
$$

where $F_{s 1}$ and $F_{r 1}$ are the 1st harmonics of the stator and the rotor MMF, respectively, $F_{c 1}$ is the composite fundamental- frequency MMF, and $\lambda_{1}$ is the angle between $F_{r 1}$ and $F_{c 1}$, as shown in Figure 1(h). 


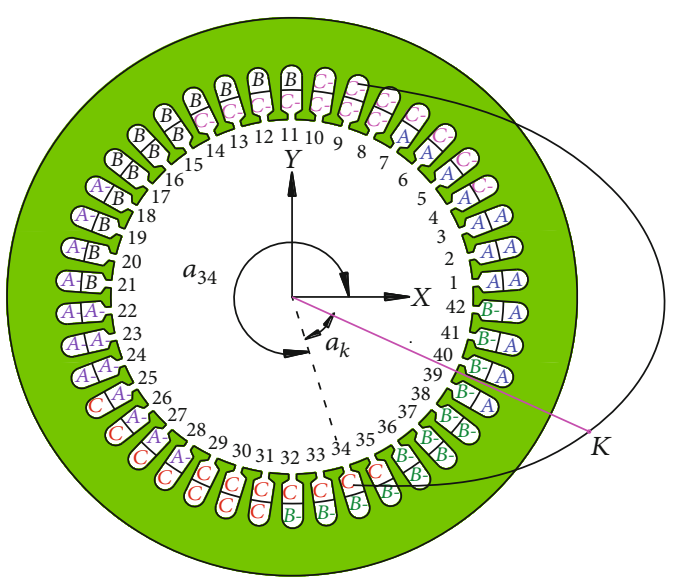

(a)

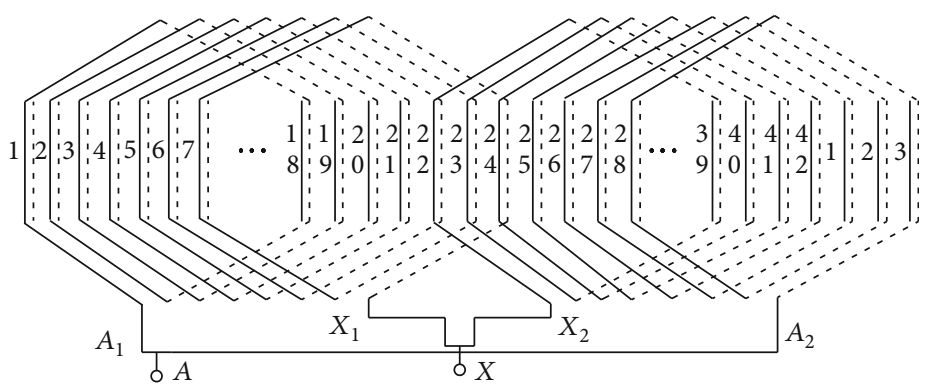

(b)

Figure 2: (a) Sectional view of three-phase winding distribution and (b) winding connection relationship of phase A.

For the sake of clarity, the circumferential angle of the upper layer of the $I$ th stator coil is defined as $\alpha_{I}$. For instance, the position of the 34th coil is defined as $\alpha_{34}$. Since there are many points on the end part of each coil, we define the circumferential position of the Kth point as $\alpha_{I}+\alpha_{k}$, as shown in
Figure 2(a). Given that the magnetic field in the end region is generally the leakage field which has a significantly smaller magnetic magnitude, we set a coefficient $f_{k}$ for the modification. Then, ignoring the higher-order harmonics of MMF, the electromagnetic force of the end winding can be obtained via

$$
\left\{\begin{array}{l}
\overrightarrow{F_{I k}}=f_{k} \vec{B} \times \overrightarrow{I_{s}} d l=\left\{\overrightarrow{F_{I k x}}, \overrightarrow{F_{I k y}}, \overrightarrow{F_{I k z}}\right\} d l, \\
F_{I k}=f_{k} B I_{s} \sin \theta_{k} \\
=\frac{1}{|Z|} f_{k} q w_{s} L v \Lambda_{0}^{2}\left(1+\varsigma \cos \left(\alpha_{I}+\alpha_{k}\right)\right)\left(1+\varsigma \cos \alpha_{I}\right) \\
\left(\sum_{n=1,3,5 \ldots} F_{c n} \cos n\left(\omega t-\alpha_{I}-\alpha_{k}-\lambda_{n}\right)\right)\left(\sum_{n=1,3,5 \ldots} k_{w n} F_{r n} \cos n\left(\omega t-\alpha_{I}-\psi-0.5 \pi\right)\right) \sin \theta_{k} \\
\approx \frac{1}{|Z|} f_{k} q w_{s} k_{w 1} L v F_{c 1} F_{r 1} \Lambda_{0}^{2} \sin \theta_{k} \cos \left(\omega t-\alpha_{I}-\alpha_{k}-\lambda_{1}\right)\left(1+\varsigma \cos \left(\alpha_{I}+\alpha_{k}\right)\right) \cos \left(\omega t-\alpha_{I}-\psi-0.5 \pi\right)\left(1+\varsigma \cos \alpha_{I}\right) \\
=\frac{f_{k} q w_{s} k_{w 1} L v F_{c 1} F_{r 1} \Lambda_{0}^{2} \sin \theta_{k} d l}{2|Z|}(1+\Delta)\left[\cos \left(\alpha_{k}+\lambda_{1}-\psi-0.5 \pi\right)+\cos \left(2 \omega t-2 \alpha_{I}-\alpha_{k}-\lambda_{1}-\psi-0.5 \pi\right)\right], \\
\Delta=\varsigma^{2} \cos \left(\alpha_{I}+\alpha_{k}\right) \cos \alpha_{I}+\varsigma \cos \left(\alpha_{I}+\alpha_{k}\right)+\varsigma \cos \alpha_{I}, \quad \alpha_{k} \in\left(0,145.7^{\circ}\right),
\end{array}\right.
$$

where $\theta_{k}$ is the angle between the magnetic flux density and the stator current at point $K$.

Further, the radial, the tangential, and the axial electromagnetic force components of coil I can be obtained through

$$
\left\{\begin{array}{l}
F_{I r}=\int_{l_{\text {end }}}\left(F_{I k x} \cos \theta+F_{I k y} \sin \theta\right) d l, \\
F_{I t}=\int_{l_{\text {end }}}\left(-F_{I k x} \sin \theta+F_{I k y} \cos \theta\right) d l, \\
F_{I a}=\int_{l_{\text {end }}} F_{I k z} d l
\end{array}\right.
$$

where $\theta$ is the vector angle of point $K$ in the cylinder coordinate, and $l_{\text {end }}$ is the coil curve of the end winding.

According to (12), the electromagnetic force on the end winding has the DC component and the 2nd harmonic. If taking into account the higher-order MMF harmonics, there should be still other even harmonics such as the 4 th, 6 th, and 8 th. The occurrence of the static rotor eccentricity will affect the amplitudes of these harmonics but will not induce new harmonics. The amplitude variation depends on the eccentricity rate $\zeta$ and the coil position $\alpha_{I}$. In this paper, $\left(\alpha_{I}+\alpha_{k}\right.$ )$\in\left(-90^{\circ}, 90^{\circ}\right)$ when $\alpha_{I} \in\left(-90^{\circ},-55.7\right)$, which results in $\Delta>$ 0 . Consequently, the electromagnetic force will be increased as the static rotor eccentricity happens. 
TABLE 1: Key parameters of the QFSN-600-2YHG turbo-generator.

\begin{tabular}{lccc}
\hline Parameter & Value & Parameter & Value \\
\hline Rated capacity & $667 \mathrm{MVA}$ & Rated exciting current & $4128 \mathrm{~A}$ \\
Rated voltage & $20000 \mathrm{v}$ & Number of stator coils in series per phase & 7 \\
Rated rotating speed & $3000 \mathrm{rpm}$ & Number of turns in per rotor slot & $8(6 \mathrm{for}$ slot 1 and slot 16) \\
Number of pole pairs & 1 & Length of rotor & $6250 \mathrm{~mm}$ \\
Connection mode of stator winding & $2 \mathrm{Y}$ & Stack length & $6300 \mathrm{~mm}$ \\
Pitch & 17 & Inner diameter of stator & $1316 \mathrm{~mm}$ \\
Power factor & 0.9 & Outer diameter of stator & $2674 \mathrm{~mm}$ \\
Operating temperature & $75^{\circ} \mathrm{C}$ & Inner diameter of rotor & $500 \mathrm{~mm}$ \\
Indexing slots of rotor & 50 & Outer diameter of rotor & $1130 \mathrm{~mm}$ \\
Real slots of rotor & 32 & Air-gap length & $93 \mathrm{~mm}$ \\
Number of stator slots & 42 & Stacking factor & 0.95 \\
Rotor slot dimensions & $60 * 40$ & Stator slot dimensions & $160 * 70$ \\
\hline
\end{tabular}

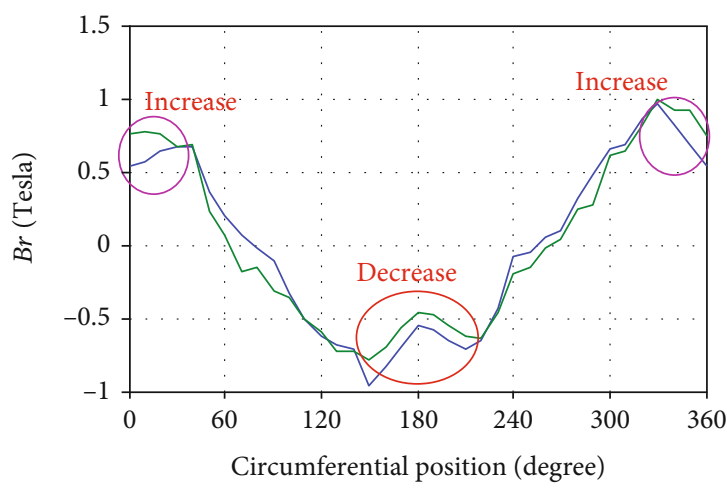

(a)

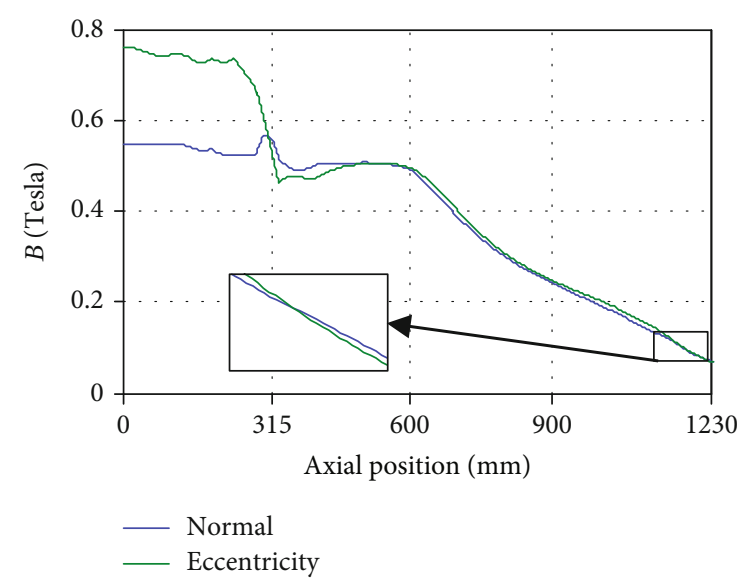

(b)

Figure 3: MFD variation: (a) circumferential distribution and (b) axial distribution.

\section{Finite Element Analysis}

3.1. Model Setup. In this paper, we take the QFSN-600-2YHG type turbo-generator as the study object, and the 3D transient solution type is employed for FEA. During the calculation, we establish the same physical model and external coupling circuit as Ref. [1]. The static rotor eccentricity is set along the $X$ axis, and the eccentricity rate is 0.03 .

The key parameters of the generator are listed in Table 1. The axial length of the stator core is $6300 \mathrm{~mm}$ which requests many computing resources in $3 \mathrm{D}$ calculation. To balance the calculation accuracy and the resource, one-tenth of the stator, namely, $630 \mathrm{~mm}$, is set for the finite element analysis [1]. The stator core has 42 slots, with the detailed slot distribution illustrated in Figure 2(a). Each slot has two layers of coils, and each coil has an upper line and a lower line inside these slots. For instance, the 34th coil has the upper line in slot 34 and the lower line in slot 9. The windings are of double $\mathrm{Y}$ connected, and the winding distribution of phase $\mathrm{A}$ is illustrated in Figure 2(b).

3.2. Electromagnetic Force. The radial magnetic flux density variation is illustrated in Figure 3(a). It shows that the mag- netic flux density curves display as a cosine function. As the eccentricity occurs, the MFD value near the 0 degree ( $X$ axis) will be increased, while near the 180 degrees, the MFD will be decreased. Such result well accords with Equation (7).

The MFD distribution in the axial direction is indicated in Figure 3(b), where the coordinate origin is set at the central point of the stator core. Since half of the stator length is $315 \mathrm{~mm}$, the MFD will obtain the larger values in $[0,315]$, while outside the stator core, the MFD amplitude will be decreased. The occurrence of the static rotor eccentricity will generally increase the MFD inside the stator core, namely, the $0-315 \mathrm{~mm}$ region.

To better analyze the electromagnetic force properties, the force of the line part and the force on the end part are calculated individually. The force density is firstly calculated. Then, the further integral operation is carried out via the field calculator to obtain the radial, the tangential, and the axial force components, respectively. The positive directions for the radial force and the axial force are set along the radial and the axial axis, respectively, both from inside to outside. For the tangential force, the positive direction is set along the forward rotating orientation. According to the aforementioned theoretical result, the electromagnetic force of the coil 


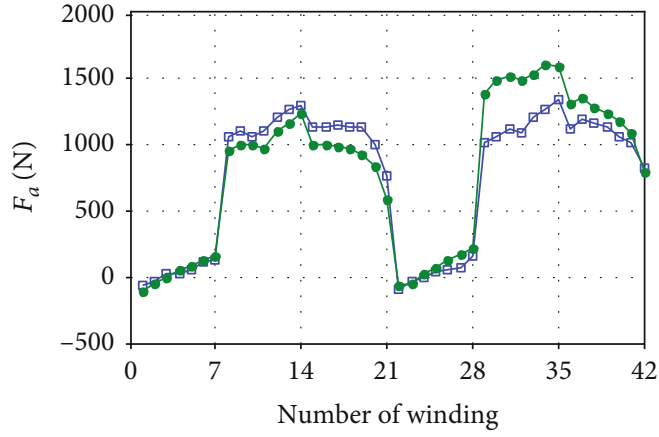

(a)

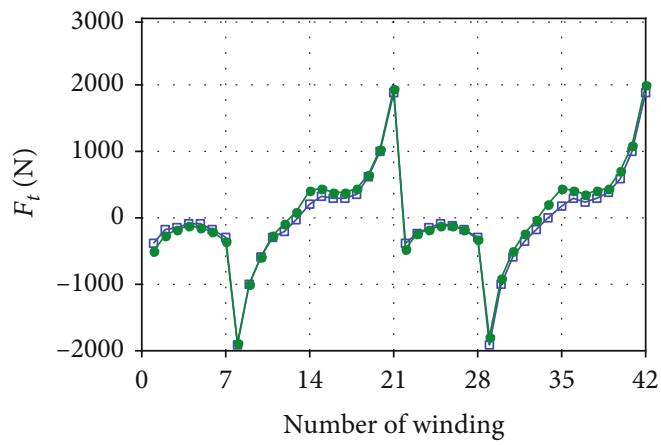

$\rightarrow$ Normal

$\longrightarrow$ Eccentricity

(c)

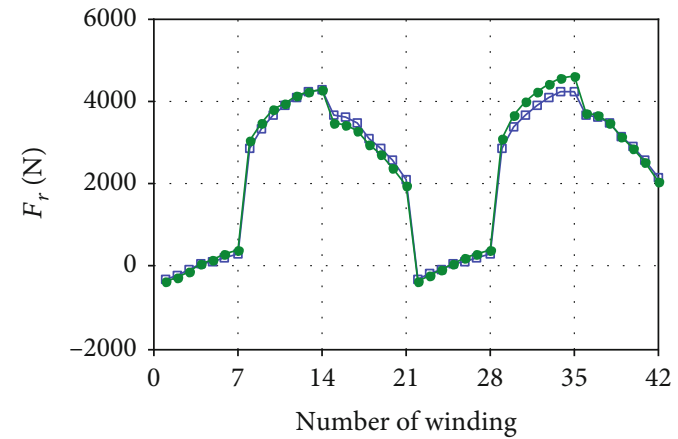

(b)

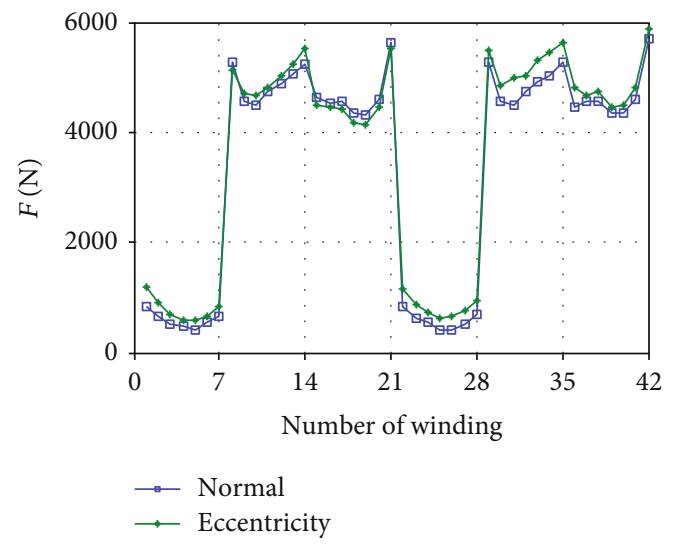

(d)

FIgURE 4: Force on windings: (a) axial force, (b) radial force, (c) tangential force, and (d) resultant force.

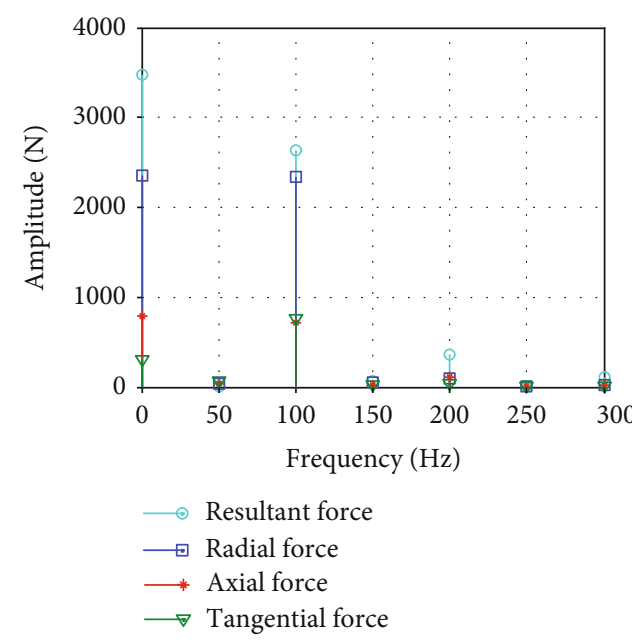

(a)

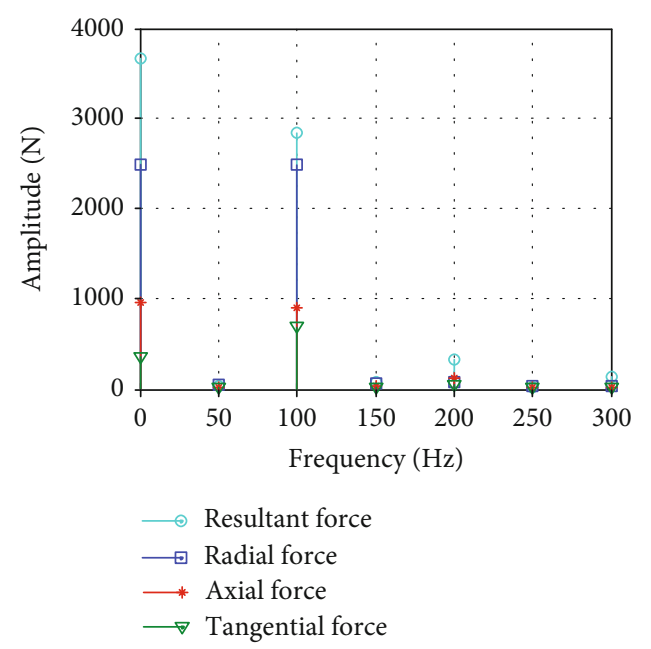

(b)

FIgURE 5: Force spectrum on coil 34: (a) normal condition and (b) eccentricity condition.

within $\left(-90^{\circ},-55.7^{\circ}\right)$ will be increased. Specifically, we set the 34th coil (the position is $-72.9^{\circ}$ ) as the particular analysis object.

The electromagnetic forces on the end windings are illustrated as Figure 4. Normally, the two coils which have the circumferential distance of 180 degrees generally have the same electromagnetic force. For instance, the 13th coil and the 34th coil illustrated in Figures 4(a)-4(d) have the same force amplitudes. This is consistent to Equation (12). However, the occurrence of static rotor eccentricity will make the magnetic flux distribution no longer even, leading to the force increment of the coils near the small air-gap side. For example, the 34th coil has an obvious force increment. As a verification, we feed the detailed angle value $\alpha_{I}=-72.9^{\circ}$ into 


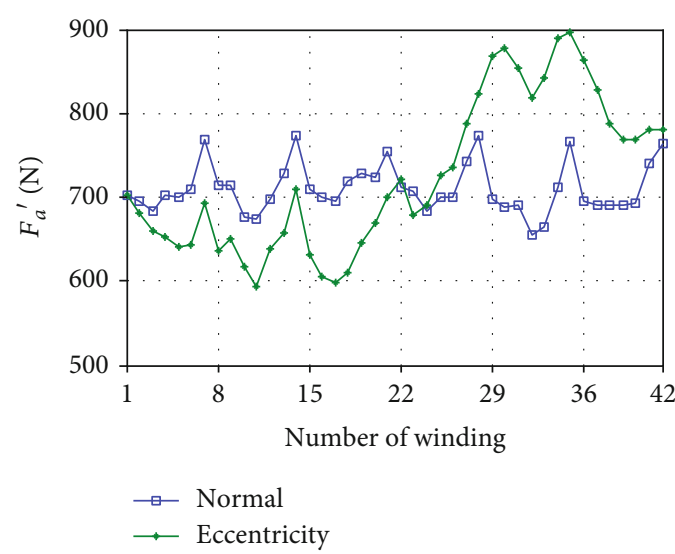

(a)

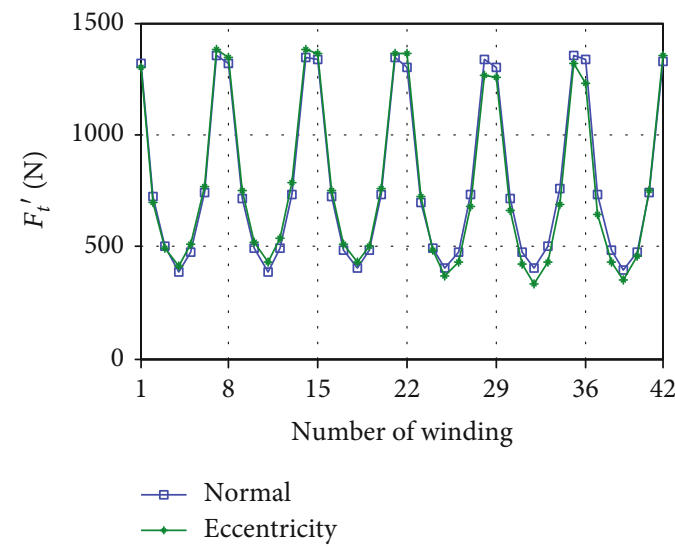

(c)

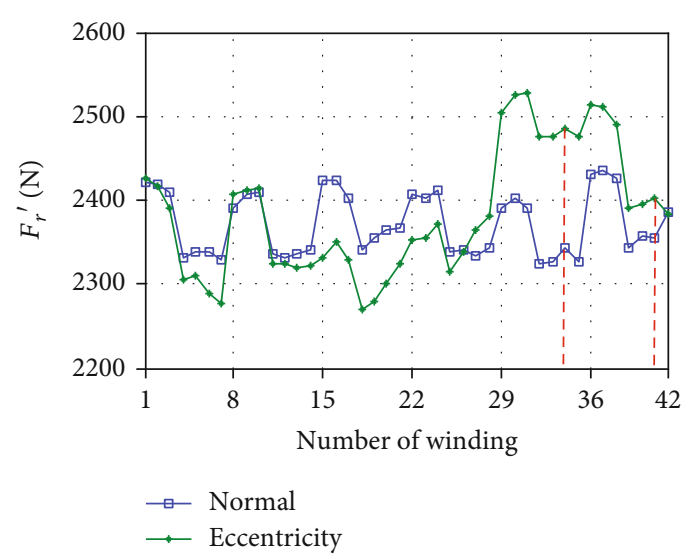

(b)

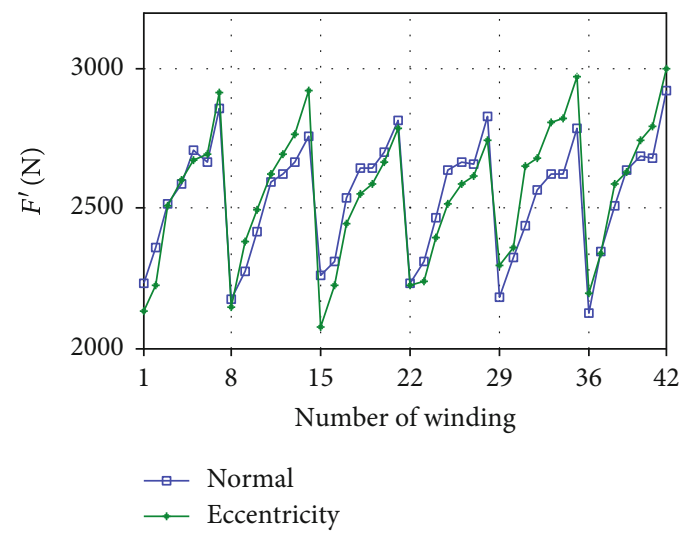

(d)

Figure 6: 2nd harmonic amplitudes of electromagnetic forces: (a) axial, (b) radial, (c) tangential, and (d) resultant force.

Equation (12) and find that $\Delta>0$, which means the force has a positive increase.

For a better illustration, the force spectra of the 34th coil before and after static rotor eccentricity are shown in Figure 5. As indicated in Figure 5, no matter in normal or the static rotor eccentricity condition, the electromagnetic forces include an obvious DC component and the 2nd harmonic. In addition, there are still other even harmonics such as the 4th and the 6th ones, but with much smaller amplitudes. Since the constant force component will not create vibrations (periodic movements/deformations) and the higher-order even harmonics are tiny, the 2nd harmonic force is the primary factor for coil vibration.

The amplitudes of the 2 nd force harmonic of each coil are illustrated in Figure 6. It is shown that the radial force component has larger force amplitudes than the tangential and the axial components. Consequently, the coils will have a more intensive vibration in the radial direction. That is why tie lines are applied to restrain the coil's radial vibration. Since the end windings are organized in two layers and constructed as a basket form, the tangential and the axial vibration will cause insulation wearing between two neighboring layers. Inside the same layer, the radial and the axial vibrations will also cause insulation wearing. Since the radial forces have larger amplitudes, the insulation wearing in the same layer will be more serious than that in different layers.
It is shown in Figure 6(d) that the phase-end coils (the last coil along the rotating direction of a phase, for instance, the 7th, 14th, 21st, 28th, and 42nd coils) have the max electromagnetic forces and therefore also the more serious vibration and insulation wearing. Moreover, the interphase coils (the coil neighboring to another phase, such as the 7th and 8th coil) have the max tangential force, as shown in Figure 6(c). Therefore, for the different-layer wearing, the interphase coil endures a larger wearing risk than the innerphase coils.

As the static rotor eccentricity happens, some coils' electromagnetic forces as well as the vibration-caused insulation wearing will be increased. Specifically, the radial and the axial force components of the 27th-41st coils will have the increasing tendencies, while the increased tangential forces will appear on the 4th-23rd coils which are about 180 degrees behind the coils that have the increasing radia1/axial forces. In general, the 29th-42nd (including the aforementioned 32 nd -36 th coils in the $\left(-90^{\circ},-55.7^{\circ}\right)$ region) coils will have the enlarged resultant forces. Such a phenomenon well accords with the previous theoretical analysis (see Equation (12)).

3.3. Mechanical Response. Due to the action of the electromagnetic forces, the coils will endure the time-varying stresses and deformations which are highly potential to cause 


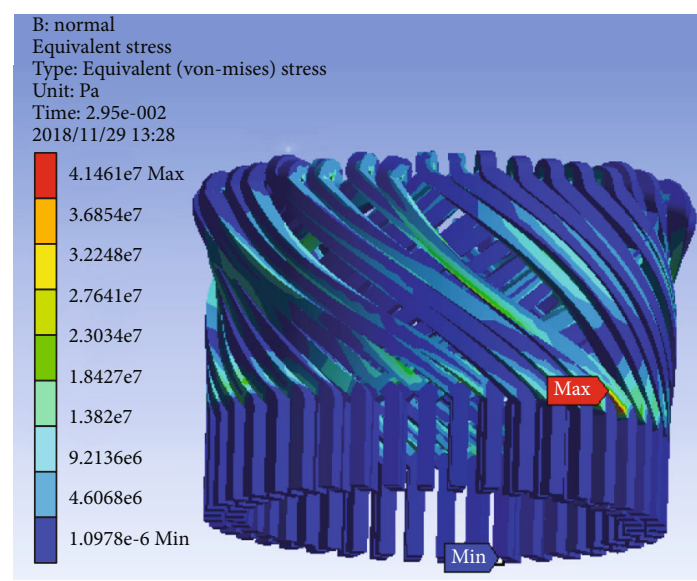

(a)

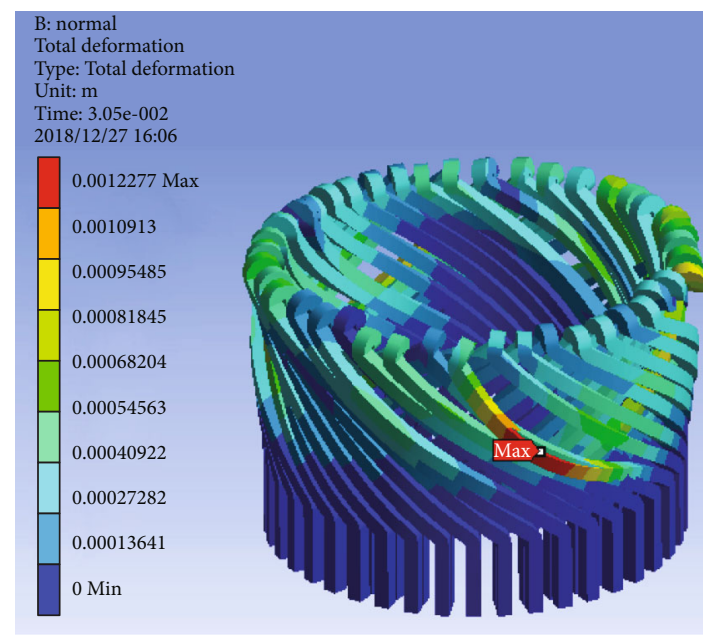

(c)

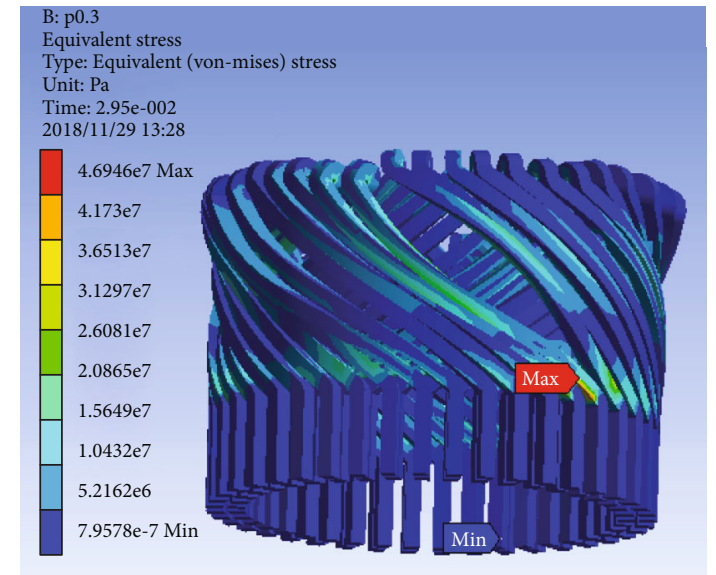

(b)

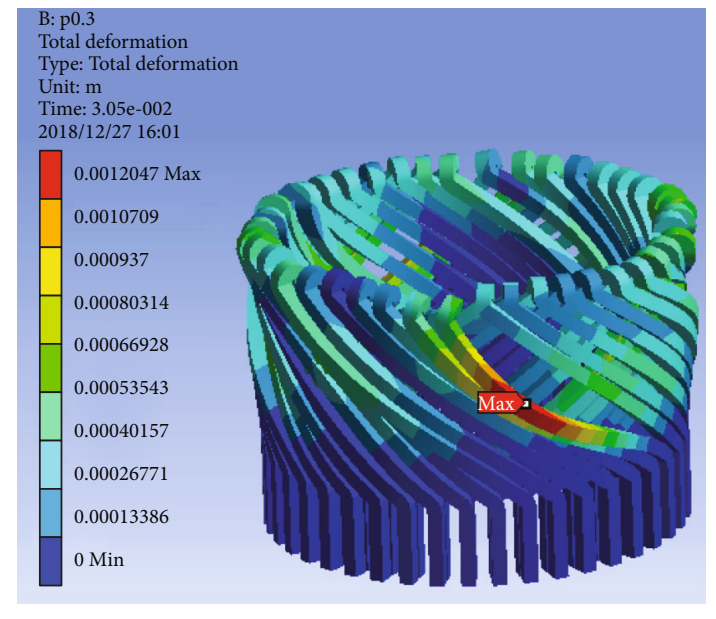

(d)

Figure 7: Mechanical response: $(a, b)$ stress and $(c, d)$ deformation in normal and eccentricity condition, respectively.

material fatigue and insulation wearing after a long period. A significant way for antiwearing is to improve the manufacturing technique, for example, spreading a wear-resistant coating on the coil surface of the dangerous region. The key point is to find out the exact dangerous region. In this paper, we carry out the multifield coupling calculation to obtain the mechanical responses such as the deformation and the equivalent stress. The electromagnetic forces are imported from the Maxwell 3D module to the transient structural module. And the detailed results are illustrated in Figure 7. It shows that the 35th coil which is at the end of phase $C$ has the max stress and deformation, since it is just next to the minimum air-gap point.

To better illustrate more details about the coil response, the 34th coil is picked as the study object and is divided into 16 segments, as indicated in Figure 8(a). The specific max stresses and deformations for each segment are shown in Figures $8(\mathrm{c})$ and $8(\mathrm{~d})$, respectively. It is shown that the max stress appears on segments $\mathrm{O}$ and $\mathrm{P}$ which are actually the root part (connecting point between the line part and the end part) of the end winding. Besides, segments $\mathrm{G}$ and $\mathrm{H}$ which are the middle part of the end winding have the second-largest stresses. For the deformation, the middle part of the end winding has the largest values (segment G). In addition, segment $\mathrm{A}$ to $\mathrm{F}$ also has an intensified deformation. Since either the overstress or the excessive deformation will lead to the potential damage to the coil, the root part and the top half near the nose are the most dangerous regions overall. These positions need specific reinforcement.

In order to explain the max stress and deformation waveform, we simplify the upper involute as a beam, and the force load analysis is shown in Figure 8(b), where $q^{\prime}$ is the electromagnetic force density whose more details can be found in Ref. [1]. $F_{1}$ is the support force provided by the stator core, $F_{2}$ is the towing force brought by the bottom involute, and they can be obtained via

$$
\left\{\begin{array}{l}
M_{\text {nose }}=F_{1} l-\int_{0}^{l} q^{\prime}(l-z) d z=0, \\
F_{1}+F_{2^{-}} \int_{0}^{l} q^{\prime} d z=0,
\end{array}\right.
$$

where $M_{\text {nose }}$ is the bending moment of the nose part, and $l$ is the beam length in the $Z$ direction. 


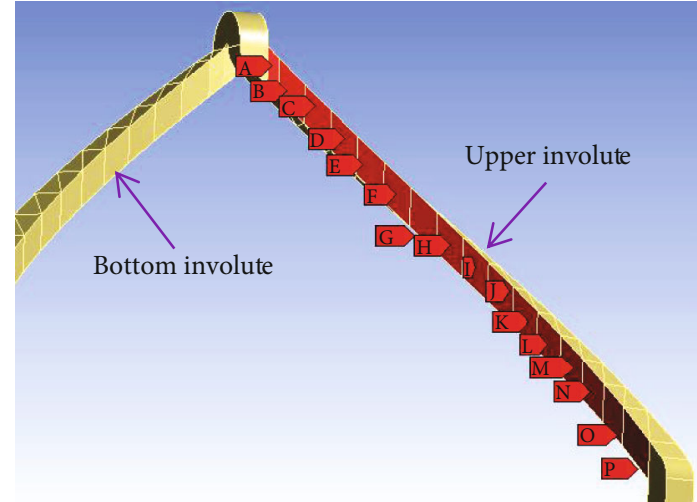

(a)

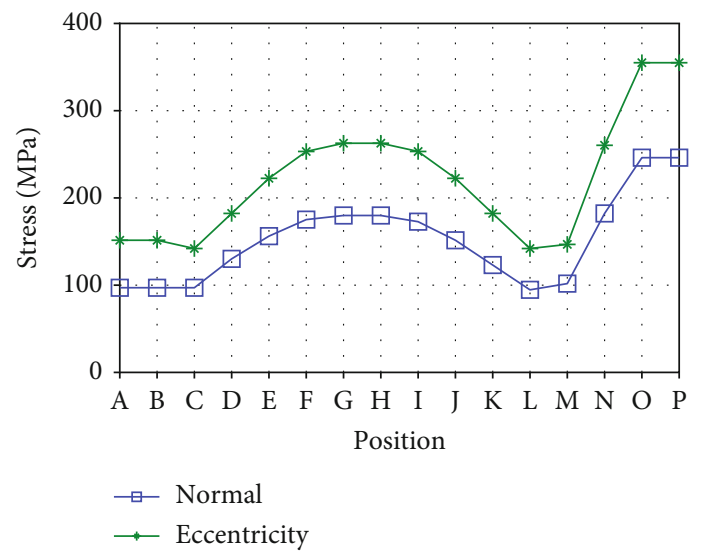

(c)

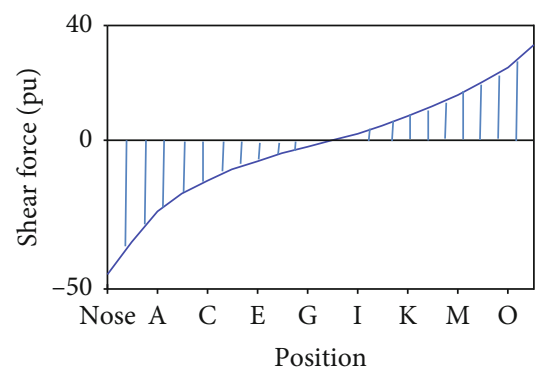

(e)

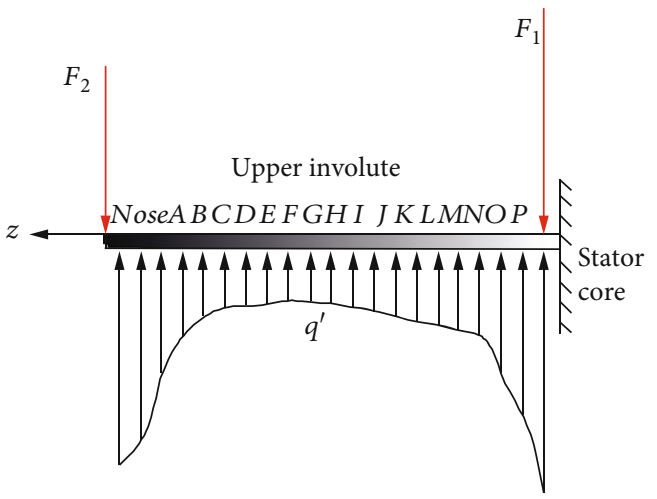

(b)

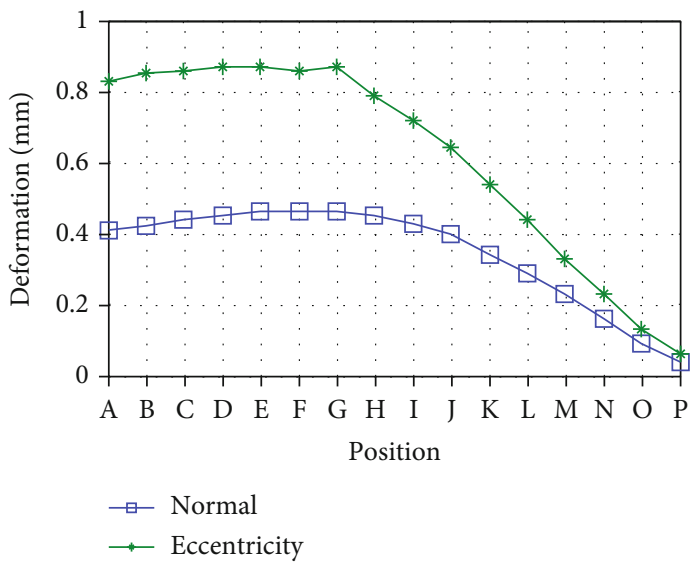

(d)

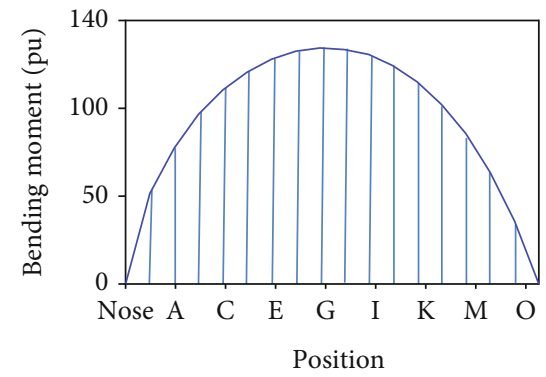

(f)

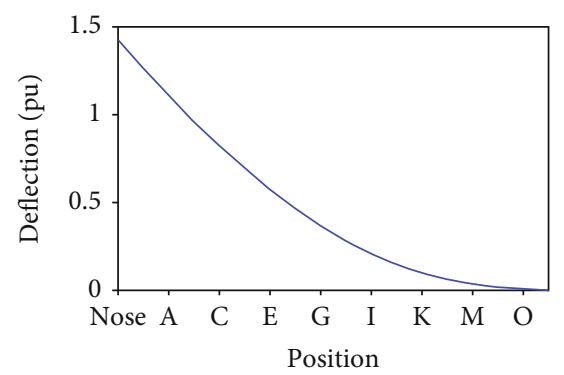

(g)

FIGURE 8: Coil 34 involute mechanical response: (a) probe position, (b) simplified model, (c) max stress, (d) max deformation, and (e-g) shear force, bending moment, and deflection, respectively.

Since the stress is related to the bending moment, we plot the schematic diagrams of the shear and the bending moments, as shown in Figures 8(e) and 8(f). It is indicated that the middle parts have the max bending moments. Therefore, the middle part will have the largest stress. This can also be further explained by the bending stress equation (15). 


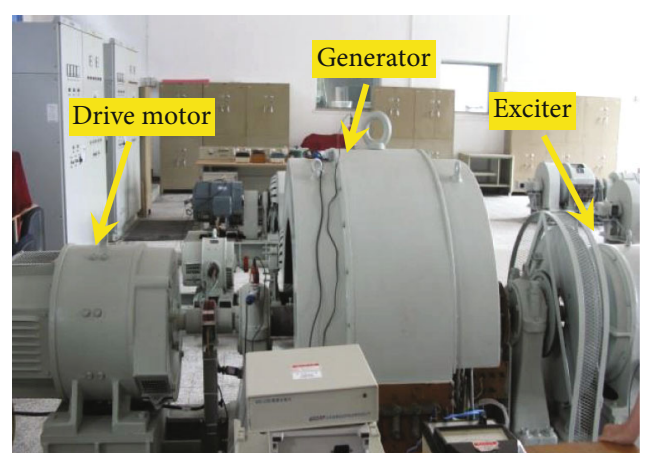

(a)

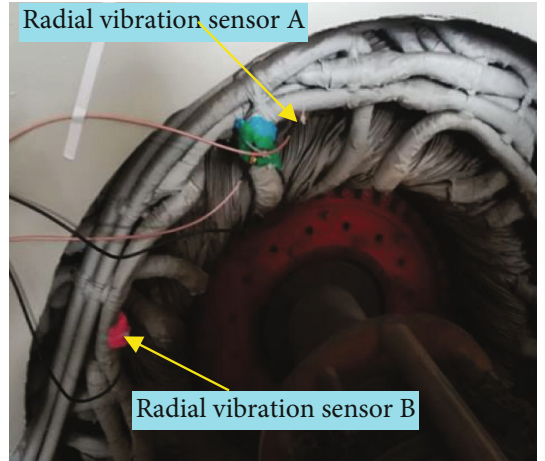

(b)

FIGURE 9: Fault simulating generator: (a) general outlook and (b) vibration sensor settings.

TABLE 2: Key parameters of the MJF-30-6 prototype generator.

\begin{tabular}{lcccccc}
\hline Parameters & Rated capacity & Rated rotation & Rated exciting current & Rated power factor & Pole pairs & Pith \\
\hline Values & $30 \mathrm{kVA}$ & $1000 \mathrm{r} / \mathrm{min}$ & $1.8 \mathrm{~A}$ & 0.8 & 3 & 8 \\
\hline
\end{tabular}

However, since the root part is the shape mutating position, it has to face the stress concentration. Consequently, the max stress actually appears on the root part, as shown in Figure 8(c).

$$
\sigma_{b}=\frac{M(z)}{W}
$$

where $M$ is the bending moment, and $W$ is the bending section coefficient.

Due to the action of the bending moment, deflections will be produced. The differential equation of the beam deflection can be written as

$$
\left\{\begin{array}{l}
f^{\prime \prime}(z)=-\frac{M(z)}{E I_{m}}, \\
f(0)=0 \\
f^{\prime}(0)=0
\end{array}\right.
$$

where $E$ is the elastic modulus, and $I_{m}$ is the inertia moment.

The deflection tendency can be obtained through the twice integration performance on the bending moment, as shown in Figure $8(\mathrm{~g})$. For the positions from $\mathrm{P}$ to $\mathrm{G}$, the deflection will generally become larger. Such a result is similar to the simulated deformation illustrated in Figure 8(d). But the deformations of $\mathrm{G}$ to $\mathrm{A}$ in Figure 8(g) are somewhat different from Figure $8(\mathrm{~d})$. This is caused by the difference between the deflection (the deformation in the radial direction, i.e., the partial deformation) and the deformation (the composite one includes not only the radial component but also others).

In engineering, the stress of the coil is hard to test due to the space limit and the data transfer difficulty inside a strong electromagnetic field circumstance. However, it is possible to test the vibration (the vibration amplitude is actually the deformation) by using the fiber optic acceleration sensors.
In this paper, we carry out the experimental study by fixing two acceleration sensors at two different coils for the vibration signal sampling and verification; more details can be found in the next section.

\section{Experiment Study}

4.1. Method. The experiments are taken on the MJF-30-6 prototype generator in the State Key Laboratory of Alternate Electric Power System with Renewable Energy Sources, China, as illustrated in Figure 9(a). The primary parameters of the generator are listed in Table 2. The air-gap is tested by a group of high-precision gauges, and the test shows that the minimum air-gap point (static rotor eccentricity position) is $120^{\circ}$, as shown in Figure 10 (a). Two accelerometers are fixed to the end winding and marked as A and B, as illustrated in Figure 9(b). Sensor A is next to the minimum airgap point, while sensor $B$ is on the coil in the neighboring phase. To be more clarified, the section diagram of the generator is displayed in Figure 10(a). Particularly, the aforementioned finite element calculation has the similar probe position as the experiment, as indicated in Figure 10(b). Sensor A is on the 34th coil, while sensor B is on the 41 st coil. The 34th coil's center is on the minimum air-gap position (see Figures 1(d) and 2(a)), and the 41 st coil is in the neighboring phase.

4.2. Results. The vibration result (acceleration signal) is illustrated in Figures 11(a)-11(d). Obviously, the 2nd harmonic is the prominent component, showing a good consistency to the previous theoretical result (see Equation (12)). Moreover, the vibration amplitude of sensor A which is closer to the minimum air-gap position is larger than that of sensor B. The simulation data of probes A (on coil 34) and B (on coil 41) shows a similar result. Such a result also matches Figure 6(b) well, and therefore, it is a good verification of the simulation. 


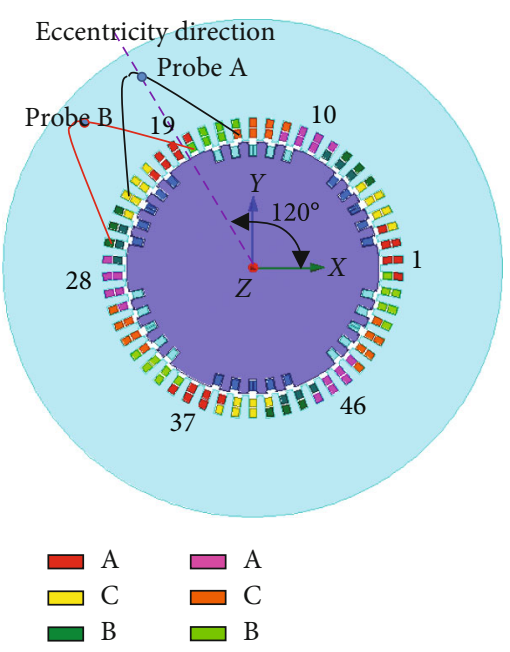

(a)

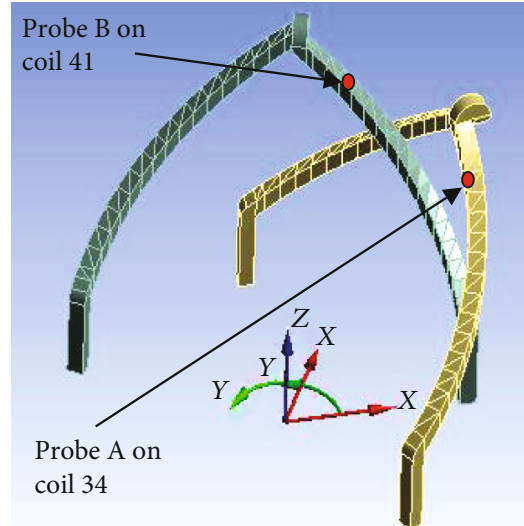

(b)

Figure 10: Probe positions of radial acceleration: (a) in experiment and (b) in simulation.

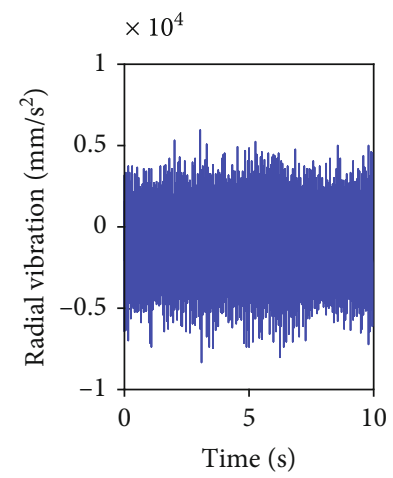

(a)

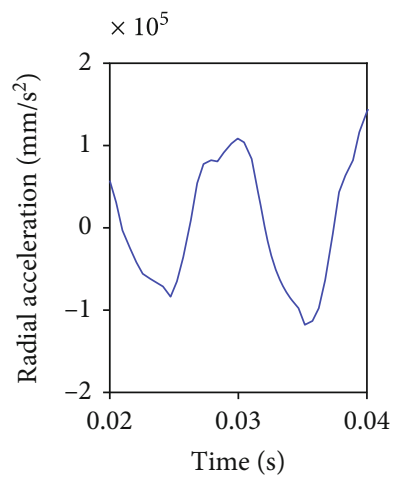

(e)

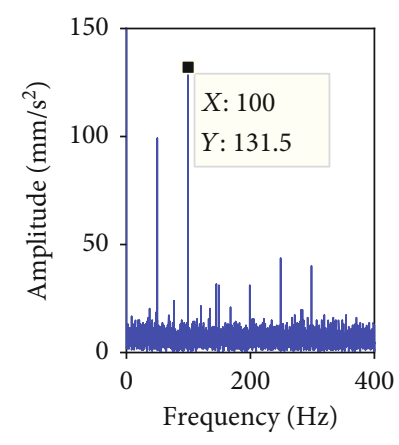

(b)

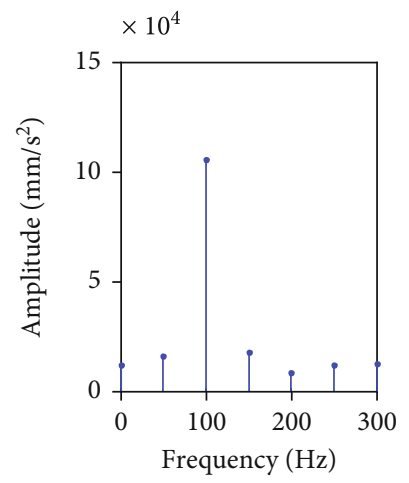

(f)

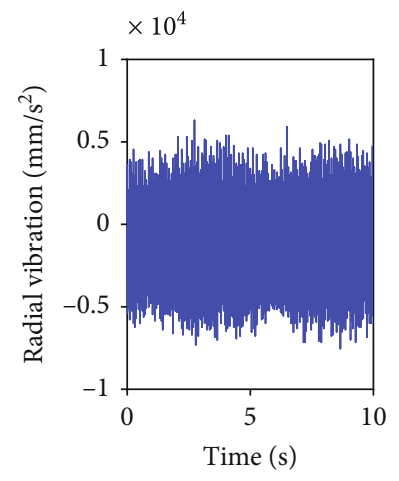

(c)

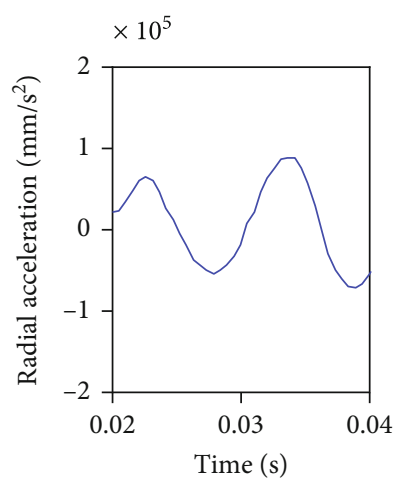

(g)

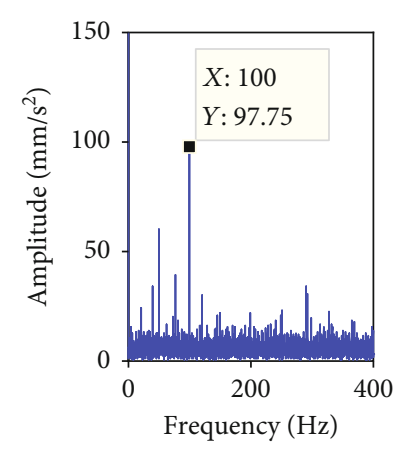

(d)

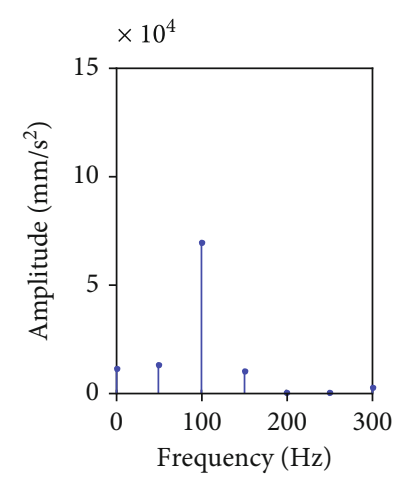

(h)

FIGURE 11: Time-domain waves and spectra of radial accelerations: (a, b) sensor A in experiment, (c, d) sensor B in experiment, (e, f) probe A in simulation, and $(\mathrm{g}, \mathrm{h})$ probe B in simulation.

\section{Conclusion}

In this paper, the electromagnetic force and the subsequent mechanical response of the stator end windings in turbogenerators before and after static rotor eccentricity are studied. The primary conclusions based on the theoretical analysis, the FEM calculation, and the experimental study can be drawn up as follows.
(1) The electromagnetic force contains a DC component and the even harmonics. The occurrence of the static rotor eccentricity will cause the force variation. The sufficient condition that the coil force will be increased is that the coil falls within the scope $\alpha_{I} \in\left(-90^{\circ},-55.7^{\circ}\right)$

(2) The radial force component is larger than both the axial and the tangential components, leading to the 
more intensified vibrations in the radial direction. As the static rotor eccentricity happens, the coils next to the minimum air-gap point will be increased

(3) The insulation wearing of the coils inside the same layer is more serious than that between two neighboring layers. For the different-layer wearing, the interphase coil endures a larger wearing risk than the innerphase coils. In normal condition, the vibration on the phase-end coils (the 7th, 14th, 21st, 28th, 35 th, and 42 nd coils) has the largest amplitude. However, in the static rotor eccentricity case, the amplified vibration will primarily appear in the 29 th- 42 nd coils

(4) Either the overstress or the excessive deformation will lead to the damage to the coil insulation. The phase-end coil which is close to the minimum airgap point is the most dangerous one. The root part and the middle part of the coil have the largest stress, while the top half near the nose has the largest deformation. These two regions need particular attention and special reinforcement during manufacturing

In the next step, the study of the electromagnetic forces on the rotor windings will be carried out as a supplement to this paper. We will conduct the same analyses for the rotor windings under normal condition and in the rotor eccentricity case, respectively.

\section{Data Availability}

The data used to support the findings of this study are available from the corresponding author upon request.

\section{Conflicts of Interest}

The authors declare that they have no conflicts of interest.

\section{Acknowledgments}

This work is supported by the National Natural Science Foundation of China (51777074), the Hebei Provincial Natural Science Foundation (E2020502032), the Top Youth Talent Support Program of Hebei Province ([2018]-27), and the Fundamental Research Funds for the Central Universities (2017MS146 and 2018YQ03).

\section{References}

[1] H.-C. Jiang, Y.-L. He, G.-J. Tang, and M.-X. Xu, “A comprehensive analysis on transient electromagnetic force behavior of stator windings in turbo-generator," Mathematical Problems in Engineering, vol. 2018, Article ID 4189609, 16 pages, 2018.

[2] J. A. Tegopoulos, "Forces on the end winding of turbinegenerators I - determination of flux densities," IEEE Transactions on Power Apparatus and Systems, vol. PAS-85, no. 2, pp. 105-113, 1966.

[3] J. A. Tegopoulos, "Forces on the end winding of turbinegenerators II - determination of forces," IEEE Transactions on Power Apparatus and Systems, vol. PAS-85, no. 2, pp. 114-122, 1966.

[4] S. Chow, Y. Lee, and E. Owen, "An integral-equation/singularity-method approach for 3-D electromagnetic field determination in the end region of a turbine-generator," IEEE Transactions on Magnetics, vol. 18, no. 2, pp. 340-345, 1982.

[5] G. K. M. Khan, G. W. Buckley, and N. Brooks, "Calculation of forces and stresses on generator end-windings. I. Forces," IEEE Transactions on Energy Conversion, vol. 4, no. 4, pp. 661-670, 1989.

[6] R. Albanese, F. Calvano, G. Dal Mut et al., "Coupled three dimensional numerical calculation of forces and stresses on the end windings of large turbo generators via integral formulation," IEEE Transactions on Magnetics, vol. 48, no. 2, pp. 875-878, 2012.

[7] K.-C. Kim and S.-J. Hwang, "Comparison study of Biot-Savart law and 3D FEM of electromagnetic forces acting on end windings," in Digests of the 2010 14th Biennial IEEE Conference on Electromagnetic Field Computation, p. 1, Chicago, IL, 2010.

[8] Y. Fang, Q. Lv, X. Cheng, and X. Bao, “Analysis of stress distribution on end winding of large water filling submersible motor during steady state operation," in 2013 5th International Conference on Power Electronics Systems and Applications(PESA), pp. 1-6, Hong Kong, 2013.

[9] Y. Fang, X. Bao, Q. Lv, X. Cheng, and Y. He, "Analysis of electromagnetic force distribution on end winding of electrical submersible motor during starting transient operation," IEEE Transactions on Magnetics, vol. 49, no. 10, pp. 5341-5345, 2013.

[10] S. J. Salon, D. J. Scott, and G. L. Kusic, "Electromagnetic forces on the end windings of large turbine generators. II. Transient conditions," IEEE Transactions on Power Apparatus and Systems, vol. PAS-102, no. 1, pp. 14-19, 1983.

[11] T. Lugand and A. Schwery, "Comparison between the salientpole synchronous machine and the doubly fed induction machine with regard to electromagnetic parasitic forces and stator vibrations," IEEE Transactions on Industry Applications, vol. 53, no. 6, pp. 5284-5294, 2017.

[12] B. Sanosian, P. Wendling, T. Pham, and W. Akaishi, "Electromagnetic Forces On Coils And Bars Inside The Slot of HydroGenerator," in 2019 IEEE energy conversion congress and exposition (ECCE), pp. 1754-1760, Baltimore, MD, USA, 2019.

[13] Y. Liang, Z. Guo, X. Bian, C. Wang, D. Wang, and L. Gao, "Novel optimization evaluation of the asymmetric-paths winding considering the electromagnetic force characteristics in AC machines," in 2019 22nd International Conference on Electrical Machines and Systems (ICEMS), pp. 1-6, Harbin, China, 2019.

[14] B. Xiaohan, W. Ting, and L. Yiling, "Electromagnetic force analysis of turbogenerator stator end winding," in 2020 5th International Conference on Electromechanical Control Technology and Transportation (ICECTT), pp. 111-115, Nanchang, China, 2020.

[15] M. Ohtaguro, K. Yagiuchi, and H. Yamaguchi, "Mechanical behavior of stator endwindings," IEEE Transactions on Power Apparatus and Systems, vol. PAS-99, no. 3, pp. 1181-1185, 1980.

[16] Y. Lu, J. Li, R. Qu, D. Ye, and H. Lu, "Electromagnetic force and vibration study on axial flux permanent magnet synchronous machines with dual three-phase windings," IEEE 
Transactions on Industrial Electronics, vol. 67, no. 1, pp. 115$125,2020$.

[17] M. R. Patel and J. M. Butler, "End-winding vibrations in large synchronous generators," IEEE Transactions on Power Apparatus and Systems, vol. PAS-102, no. 5, pp. 1371-1377, 1983.

[18] D. Mori and T. Ishikawa, "Force and vibration analysis of induction motors," IEEE Transactions on Magnetics, vol. 41, no. 5, pp. 1948-1951, 2005.

[19] H. Yang and Y. Chen, "Influence of radial force harmonics with low mode number on electromagnetic vibration of PMSM," IEEE Transactions on Energy Conversion, vol. 29, no. 1, pp. 38-45, 2014.

[20] F. Ishibashi, M. Matsushita, S. Noda, and K. Tonoki, "Change of mechanical natural frequencies of induction motor," IEEE Transactions on Industry Applications, vol. 46, no. 3, pp. 922-927, 2010.

[21] A. Ghaempanah and J. Faiz, "Impact of rotor winding and stator stepped end core on magnetic force distribution on stator end-winding of turbogenerators," in 2015 IEEE Jordan Conference on Applied Electrical Engineering and Computing Technologies (AEECT), pp. 1-6, Amman, 2015.

[22] W. Li, P. Wang, J. Li, L. Wang, S. Gong, and D. Li, "Influence of stator parameter variation and phase-shift under synchronizing out of phase on turbine generator electromagnetic field," IEEE Transactions on Energy Conversion, vol. 32, no. 2, pp. 525-533, 2017.

[23] Y. He, M.-X. Xu, W. Zhang et al., "Impact of stator interturn short circuit position on end winding vibration in synchronous generators," IEEE Transactions on Energy Conversion, p. 1,2020 .

[24] Q. Meng and Y. He, "Mechanical response before and after rotor inter-turn short-circuit fault on stator windings in synchronous generator," in 2018 IEEE Student Conference on Electric Machines and Systems, pp. 1-7, HuZhou, China, 2018.

[25] Y.-L. He, M.-Q. Ke, F.-L. Wang, G.-J. Tang, and S.-T. Wan, "Effect of static eccentricity and stator inter-turn short circuit composite fault on rotor vibration characteristics of generator," Transactions of the Canadian Society for Mechanical Engineering, vol. 39, no. 4, pp. 767-781, 2015.

[26] Y. He, Z.-J. Zhang, W.-Q. Tao et al., “A new external search coil based method to detect detailed static air-gap eccentricity position in non-salient pole synchronous generators," IEEE Transactions on Industrial Electronics, p. 1, 2020.

[27] H. Ehya, I. Sadeghi, and J. Faiz, "Online condition monitoring of large synchronous generator under eccentricity fault," in 2017 12th IEEE Conference on Industrial Electronics and Applications (ICIEA), pp. 19-24, Siem Reap, 2017.

[28] Y.-L. He, M.-X. Xu, J. Xiong et al., "Effect of 3D unidirectional and hybrid SAGE on electromagnetic torque fluctuation characteristics in synchronous generator," IEEE Access, vol. 7, pp. 100813-100823, 2019.

[29] Y.-. L. He, Y.-. X. Sun, M.-. X. Xu et al., "Rotor UMP characteristics and vibration properties in synchronous generator due to 3D static air-gap eccentricity faults," IET Electric Power Applications, vol. 14, no. 6, pp. 961-971, 2020.

[30] W. Doorsamy, A. A.-E. Abdallh, W. A. Cronje, and L. Dupre, "An experimental design for static eccentricity detection in synchronous machines using a Cramér-Rao lower bound technique," IEEE Transactions on Energy Conversion, vol. 30, no. 1, pp. 254-261, 2015. 